Data processing. The criterion for threshold was the boundary between a block showing one response (action potential) per five trials and a block showing no response per five trials. In unanaesthetized bats the response magnitude and background discharge rate of thalamic and collicular neurons fluctuated to some extent. Therefore, the threshold was determined with additional criteria. If a given block showed at least one response per five trials, it was interpreted to be within an excitatory area demarcated by a tuning curve. If it showed no response per five trials, but the adjacent blocks, away from the excitatory area, showed at least one response per five trials, the given block was put within the excitatory area. Because auditory responses always occurred within a time window of $50 \mathrm{~ms}$ with relatively constant latencies ranging between 5 and $12 \mathrm{~ms}$, and background discharge rate was low $\left(0.58 \pm 0.32 \mathrm{~s}^{-1}\right.$ for 17 collicular neurons and $0.85 \pm 0.43 \mathrm{~s}^{-1}$ for 16 thalamic neurons), auditory responses were easily distinguished from background discharges.

We established the criteria for a shift in frequency tuning as follows. If frequency-response or frequency-tuning curves shifted by cortical inactivation with Lidocaine did not recover to more than $50 \%$ of their earlier value they were excluded from our analysis. The fact that almost all curves shifted by Lidocaine recovered by more than $50 \%$ indicates that the shift was significant. To ensure that the shift was significant we used the following procedure. For individual frequency-response curves, a weighted average frequency (best frequency) was calculated for the summed responses to 5 consecutive frequency scans. We obtained 10 such values to calculate the mean \pm s.d. We used a twotailed, paired $t$-test to determine whether or not the weighted average frequencies (best frequencies) obtained for control and Lidocaine conditions were significantly different (at $P<0.01$ ). Frequency-tuning curves were based upon the threshold measurement, so s.d. could not be calculated for each data point. We therefore applied the following criterion: shifts in best frequencies and frequency-tuning curves evoked by Lidocaine were considered to be significant if the shift in best frequency was accompanied by shifts of more than $75 \%$ of the data points in the same direction as that of the best-frequency shift.

Received 31 December 1996; accepted 25 April 1997.

1. Suga, N. Cortical computational maps for auditory imaging. Neural Networks 3, 3-21 (1990).

2. Huffman, R. F. \& Henson, O. W. Jr The descending auditory pathway and acousticomotor system: connections with the inferior colliculus. Brain Res. 15, 295-323 (1990)

3. Andersen, R. A. et al. The topographic organization of corticocollicular projections from physiologically identified loci in the AI, AII, and anterior auditory cortical field of the cat. J. Comp. Neurol. 191, 479-494 (1980).

4. Herbert, H. et al. Topography of projections from the auditory cortex to the inferior colliculus in the rat. J. Comp. Neurol. 304, 103-122 (1991).

Massopust, L. C. Jr \& Ordy, J. M. Auditory organization of the inferior colliculus in the cat. Exp. Neurol. 6, 465-477 (1962).

6. Andersen, P. et al. Corticofugal facilitation of thalamic transmission. Brain Behav. Evol. 6, 170-184 (1972).

Ryugo, D. K. \& Weinberger, N. M. Corticofugal modulation of the medial geniculate body. Exp. Neurol. 51, 377-391 (1976).

8. Mitani, A. et al. Effects of simulation of the primary auditory cortex upon colliculogeniculate neurons in the inferior colliculus of the cat. Neurosci. Lett. 42, 185-189 (1983).

9. Sun, X. et al. Corticofugal influences on the responses of bat inferior colliculus to sound stimulation. Brain Res. 495, 1-8 (1989).

10. Villa, A. P. E. et al. Corticofugal modulation of the information processing in the auditory thalamus of the cat. Exp. Brain Res. 86, 506-517 (1991).

11. Suga, N. et al. in Active Hearing (eds Ottoson, A. F. D. \& Ulfendahl, M.) 13-30 (Pergamon, London, 1995).

12. Yan, J. \& Suga, N. Corticofugal modulation of time-domain processing of biosonar information in bats. Science 273, 1100-1103 (1996)

13. Johnson, R. A. et al. Detection of insect wing beats by the bat, Pteronotus parnellii. J. Acoust. Soc. Am 55, S53 (1974).

14. Goldman, L. J. \& Henson, O. W. Jr Prey recognition and selection by the constant frequency bat, Pteronotus p. parnellii. Behav. Ecol. Sociobiol. 2, 411-419 (1977).

15. Suga, N. et al. Peripheral specialization for fine analysis of Doppler-shifted echoes in the auditory system of the "CF-FM" bat Pteronotus parnelli. Exp. Biol. 63, 161-192 (1975).

16. Suga, N. \& Jen, P. H. S. Disproportionate tonotopic representation for processing species-specific CFFM sonar signals in the mustahced bat auditory cortex. Science 194, 542-544 (1976).

17. Suga, N. \& Manabe, T. Neural basis of amplitude-spectrum representation in auditory cortex of the mustached bat. J. Neurophysiol. 47, 225-255 (1982).

18. Suga, N. \& Tsuzuki, K. Inhibition and level-tolerant frequency-tuning curves in the auditory cortex of the mustached bat. J. Neurophysiol. 53, 1109-1145 (1985).

19. Yang, L. et al. GABAergic circuits sharpen tuning curves and modify response properties in the mustached bat inferior colliculus. J. Neurophysiol. 68, 1760-1774 (1992).

20. Suga, N. et al. Sharpening of frequency tuning by inhibition in the thalamic auditory nucleus of the mustached bat. J. Neurophysiol. 77, 2098-2114 (1997).

21. Suga, N. Sharpening of frequency tuning by inhibition in the central auditory system: Tribute to Yasuji Katsuki. Neurosci. Res. 21, 287-299 (1995)

22. Olsen, J. F. thesis, Washington University (1986).

23. Winer, J. A. in The Mammalian Auditory Pathway: Neuroanatomy (eds Webster, D. B., Popper, A. N. \& Fay, R. R.) 222-410 (Springer, New York, 1992)

24. Suga, N. et al. The personalized auditory cortex of the mustached bat: adaptation for echolocation. J. Neurophysiol. 58, 643-654 (1987).
25. Edeline, J. M. \& Weinberger, N. M. Subcortical adaptive filtering in the auditory system: associative receptive field plasticity in the dorsal medial geniculate body. Behav. Neurosci. 105, 154-175 (1991) 26. Edeline, J. M. \& Weinberger, N. M. Associative returning in the thalamic source of input to the amygdala and auditory cortex: receptive field plasticity in the medial division of the medial geniculate body. Behav. Neurosci. 106, 81-105 (1992).

27. Edeline, J. M. et al. Rapid development of learning-induced receptive field plasticity in the auditory cortex. Behav. Neurosci. 107, 539-551 (1993).

28. Suga, N. et al. Specificity of combination-sensitive neurons for processing of complex biosonar signals in the auditory cortex of the mustached bat. J. Neurophysiol. 49, 1573-1626 (1983).

Acknowledgements. We thank the Natural Resource Conservation Authority and the Ministry of agriculture of Jamaica for allowing us to collect and export the moustached bats used in our research. We thank S. Kuwada, W. E. ONeill, J. F. Olsen, D. C. Fitzpatrick and A. Kadir for helpful comments.

\section{Congenital leptin deficiency is associated with severe early-onset obesity in humans}

\author{
Carl T. Montague ${ }^{\star} \dagger$, I. Sadaf Farooqi ${ }^{*} \dagger \neq$, \\ Jonathan P. Whitehead ${ }^{\star} \ddagger$, Maria A. Soos ${ }^{\star} \ddagger$, Harald Rau ${ }^{\star} \ddagger$, \\ Nicholas J. Wareham $₫$, Ciaran P. Sewter ${ }^{\star}$, \\ Janet E. Digby $\ddagger$, Shehla N. Mohammed\|, Jane A. Hurstg, \\ Christopher H. Cheetham\#, Alison R. Earley\#, \\ Anthony H. Barnett $九$, Johannes B. Prins ${ }^{\star} \ddagger$ \\ \& Stephen O'Rahilly $¥$
}

University of Cambridge, Departments of ${ }^{\star}$ Medicine, $\ddagger$ Clinical Biochemistry and $\$$ Community Medicine, Addenbrooke’s Hospital, Hills Road,

Cambridge CB2 2QR, UK

\| South Thames Regional Genetics Centre (East), Guy's Hospital, London SE1 9RT, UK

I Oxford Regional Genetics Service, Churchill Hospital, Oxford OX3 7LJ, UK

\# Wycombe General Hospital, Queen Alexandra Road, High Wycombe,

Buckinghamshire HP11 2TT, UK

Department of Medicine, University of Birmingham and Birmingham

Heartlands Hospital, Birmingham B9 5SS, UK

$\dagger$ These authors contributed equally to this study.

The extreme obesity of the obese (ob/ob) mouse is attributable to mutations in the gene encoding leptin ${ }^{1}$, an adipocyte-specific secreted protein which has profound effects on appetite and energy expenditure. We know of no equivalent evidence regarding leptin's role in the control of fat mass in humans. We have examined two severely obese children who are members of the same highly consanguineous pedigree. Their serum leptin levels were very low despite their markedly elevated fat mass and, in both, a homozygous frame-shift mutation involving the deletion of a single guanine nucleotide in codon 133 of the gene for leptin was found. The severe obesity found in these congenitally leptindeficient subjects provides the first genetic evidence that leptin is an important regulator of energy balance in humans.

In 1994, two different strains of $o b / o b$ mice were reported to have defects in the gene encoding leptin, a previously unknown secreted fat-cell product ${ }^{1}$. Leptin is thought to act primarily at the hypothalamus, where it has effects on appetite, energy expenditure and neuroendocrine axes ${ }^{2-4}$. Treatment of $o b / o b$ mice with biosynthetic leptin corrects all of their phenotypic abnormalities ${ }^{5-7}$. Further, the administration of large amounts of leptin to normal rats and mice markedly reduces body fat stores, suggesting that, at least in rodents, leptin may influence body fat mass across a range of serum concentrations $^{8}$. A role for leptin deficiency in human obesity has been considered but no pathogenic mutations in the gene that encodes leptin have previously been found in obese humans ${ }^{9,10}$. Despite considerable evidence that genetic factors contribute to human obesity ${ }^{11}$, no mutations in any gene have been reported to cause obesity in humans. We have studied two related children with 
extreme obesity, and our observations indicate that their obesity is due to a congenital deficiency in the production of leptin.

The two children, here referred to as $\mathrm{Ob} 1$ and $\mathrm{Ob} 2$, are cousins within a highly consanguineous family of Pakistani origin. Although of normal weight at birth, both children suffered from severe, intractable obesity from an early age. The children have no additional clinical features to suggest that they might have a pleiotropic genetic syndrome associated with obesity, such as
Alstrom's or Prader-Willi syndrome. Previous investigations have included normal karyotypes and normal computer tomography (CT) of the brain of Ob1. Each child has two siblings of normal weight, and none of their parents are morbidly obese. Informed parental consent was obtained for all studies, and ethical permission was granted by the Cambridge Local Research Ethics Committee.

To examine whether a mutation in the gene that encodes leptin might underly severe obesity in subject $\mathrm{Ob} 2$, the nucleotide

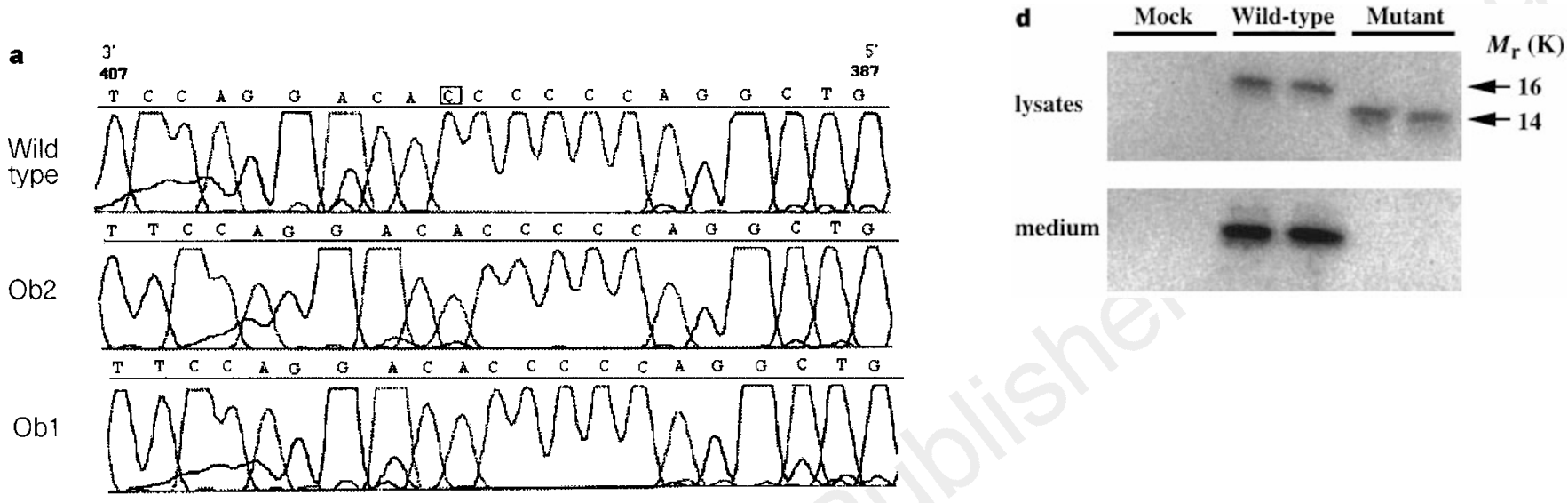

b

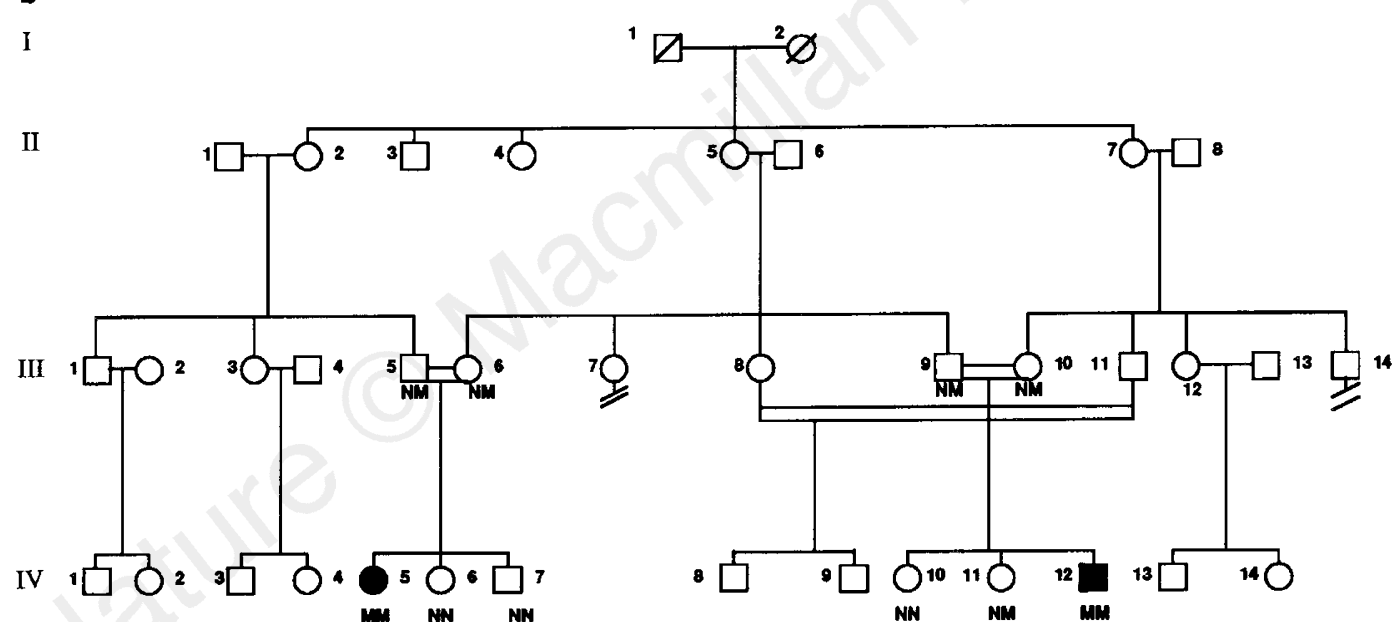

C

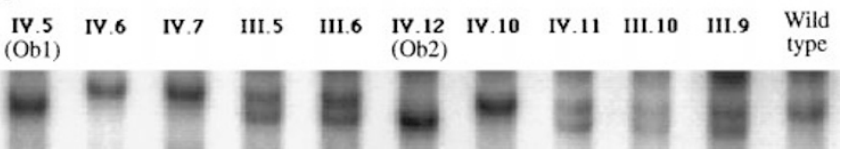

Figure 1 a, Detection of a homozygous frame-shift mutation in the leptin genes of probands Ob1 and Ob2. Adipocyte RNA was isolated from a needle biopsy of subcutaneous adipose tissue obtained from Ob2. RNA was reverse-transcribed and the nucleotide sequence encoding the leptin protein was amplified by PCR and subcloned, and four subclones were sequenced. The nucleotide sequence provided by the automated sequencing apparatus corresponds to the reverse complement of the coding sequence. In all four clones of Ob2's leptin cDNA, five, rather than the expected six, guanine nucleotides were present between nucleotides 393 and 398. The same region of the leptin coding sequence was amplified from genomic DNA of Ob1 and an unrelated control subject. The leptin gene of the control subject has six guanines $(G)$ in the appropriate position (shown as cysteines $(C)$, as the reverse complement strand was sequenced), whereas Ob1 is homozygous for the deleted guanine. b, c, Individuals with severe early-onset obesity are indicated by black symbols. The genotype, if known, is indicated below the symbol: N, normal; M, leptin mutation. Clinically unaffected

family members are not homozygotes for the frame-shift mutation. The inheritance of the leptin frame-shift mutation in available first-degree relatives of $\mathrm{Ob} 1$ and Ob2 was examined by PCR-SSCP $(\mathbf{c})$. The mutant sequence resulted in a readily detectable mobility shift, which was clearly seen in homozygous form in $\mathrm{Ob} 1$ and Ob2. As expected, all four parents were heterozygotes. Of the siblings of the probands, three were homozygous for the wild-type sequence, and one was a heterozygote. These results were confirmed by direct sequencing (data not shown). d, The secretion of mutant leptin is impaired. $\mathrm{CHO}$ cells were transiently transfected with expression vectors encoding either mutant or wild-type leptin. Leptin immunoreactivity was examined in cell lysates (top) and in the medium (bottom) by immunoprecipitation, SDS-PAGE and western blotting. With wildtype leptin, the expected band at $16 \mathrm{~K}$ is seen in both the cell lysate and the medium, whereas, in cells transfected with mutant leptin, no leptin is seen in the medium, although a truncated $14 \mathrm{~K}$ species is detectable in the lysate. 
sequence of leptin cDNA (Genbank accession no. U18915) was examined. Leptin cDNA was generated from reverse-transcribed RNA isolated from $20 \mathrm{mg}$ of subcutaneous adipose tissue obtained by needle biopsy. Polymerase chain reaction (PCR) products were subcloned and four independent clones sequenced. All clones from subject $\mathrm{Ob} 2$ contained a frame-shift mutation in the leptin-coding region consisting of the deletion of a single guanine nucleotide normally present in codon 133 (see Fig. 1a for the reverse complement sequence). Both $\mathrm{Ob} 1$ and $\mathrm{Ob} 2$ were confirmed to be homozygous for this deletion by direct sequencing of PCR products of the leptin gene amplified from their genomic DNA (Fig. 1a). The mutation disrupts the reading frame of the leptin gene, leading to the introduction of 14 aberrant amino acids after Gly 132 in the native leptin polypeptide, followed by a premature stop codon.

To examine the co-segregation of the leptin gene mutation with body fat content in this pedigree, 176 base pairs of the leptin gene encompassing the site of the deleted guanine nucleotide were examined by $\mathrm{PCR}$-single strand conformation polymorphism (SSCP) analysis in the probands and their available first-degree relatives using genomic DNA isolated from blood leukocytes as a template. The mutation resulted in a readily detectable mobility shift, which was seen in homozygous form in both Ob1 and Ob2

\begin{tabular}{|c|c|c|c|}
\hline & Ob1 & Ob2 & Reference range \\
\hline fasting glucose & 4.7 & 4.4 & $3.5-5.5 \mathrm{mmoll}^{-1}$ \\
\hline insulin & 158 & 46 & $0-60 \mathrm{pmoll}^{-1}$ \\
\hline proinsulin & 21 & 8.1 & $0-5 \mathrm{pmoll}^{-1}$ \\
\hline 32-33 split proinsulin & 39 & 11 & $<13 \mathrm{pmoll}^{-1}$ \\
\hline 9:00 ACTH & 58 & 28 & $5-50 \mathrm{ngl}^{-1}$ \\
\hline 9:00 cortisol & 420 & 156 & $280-650 \mathrm{nmol}^{-1}$ \\
\hline TSH & 4.80 & 4.6 & $0.4-4 \mathrm{mUl}^{-1}$ \\
\hline free $T 4$ & 11.4 & 12.4 & $9-20 \mathrm{pmoll}^{-1}$ \\
\hline $\mathrm{FSH}$ & 0.8 & 0.2 & prepubertal 0.6-3.4 UI $\mathrm{I}^{-1}$ \\
\hline $\mathrm{LH}$ & $<0.2$ & $<0.2$ & prepubertal 0.6-1.7 $\mathrm{UI}^{-1}$ \\
\hline oestradiol & $<20$ & - & prepubertal $<60 \mathrm{pmol}^{-1}$ \\
\hline testosterone & - & $<0.2$ & prepubertal $<0.7 \mathrm{nmoll}^{-1}$ \\
\hline
\end{tabular}

Levels of testosterone, oestradiol, luteinizing hormone (LH) and follicle-stimulating hormone (FSH) are all consistent with the prepubertal state. Ob1 has marked fasting hyperinsulinaemia and a mild elevation in 9:00 levels of adrenocorticotropic hormone (ACTH) and thyrotropic hormone (TSH).
(Fig. 1c). As expected, all four parents were heterozygotes. Of the four siblings of the probands, one was a heterozygote and three were homozygous for the wild-type sequence (Fig. 1b, c). The genotype of all family members was confirmed by nucleotide sequencing. The mutation was not found by SSCP analysis in 108 alleles of UK control subjects of Pakistani origin.

Chinese hamster ovary $(\mathrm{CHO})$ cells were transiently transfected with expression vectors encoding either wild-type or mutant leptin cDNA. Although $16 \mathrm{~K}$ wild-type leptin was readily detectable in the medium by immunoprecipitation, SDS-polyacrylamide gel electrophoresis (SDS-PAGE) and western blotting, no secreted mutant leptin was detected (Fig. 1d). The absence of mutant leptin in the medium was not due to failure of the antibodies to recognize the mutant leptin because, when cells expressing the mutant leptin were lysed, a $14 \mathrm{~K}$ truncated species was readily detected (Fig. 1d). It is therefore likely that the frame-shift mutation results in a form of leptin which is not targeted normally for secretion.

To examine whether homozygosity for this frame-shift mutation was associated with abnormalities in circulating leptin, serum leptin levels were measured by radio-immunoassay in Ob1 and Ob2 and found to be close to the limits of detection of this assay at 1.0 and $0.7 \mathrm{ng} \mathrm{ml}^{-1}$, respectively. The mean ( \pm s.d.) serum leptin levels found in 16 normal prepubertal children was $8 \pm 4.5 \mathrm{ng} \mathrm{ml}^{-1}$, and in 30 adults was $23 \pm 10 \mathrm{ng} \mathrm{ml}^{-1}$. Because serum leptin levels show a strong positive correlation with indices of obesity ${ }^{12}$ (see Fig. 2), the finding of barely detectable levels of serum leptin in these two extremely obese children was notable. As the leptin levels measured by radio-immunoassay were very low, serum leptin levels in Ob1 and $\mathrm{Ob} 2$ were examined further using a highly sensitive solid-phase sandwich enzyme immunoassay. Serum leptin levels in Ob1 and Ob2 were 0.11 and $0.38 \mathrm{ng} \mathrm{ml}^{-1}$, respectively, again close to the detection limit of this assay $\left(0.07 \mathrm{ng} \mathrm{ml}^{-1}\right)$. Finally, no immunoreactive leptin was detected in the serum of Ob2 by western blotting. A band identical to the recombinant standard $16 \mathrm{~K}$ was readily detected in serum from all four heterozygote adults, but no immunoreactive material of lower molecular weight was seen in the serum of these subjects (M. Nicolson, data not shown). As the antibodies used to detect leptin in all three assay systems were polyclonal and raised to the entire protein, it is possible that we have understimated the circulating concentrations of the mutant leptin

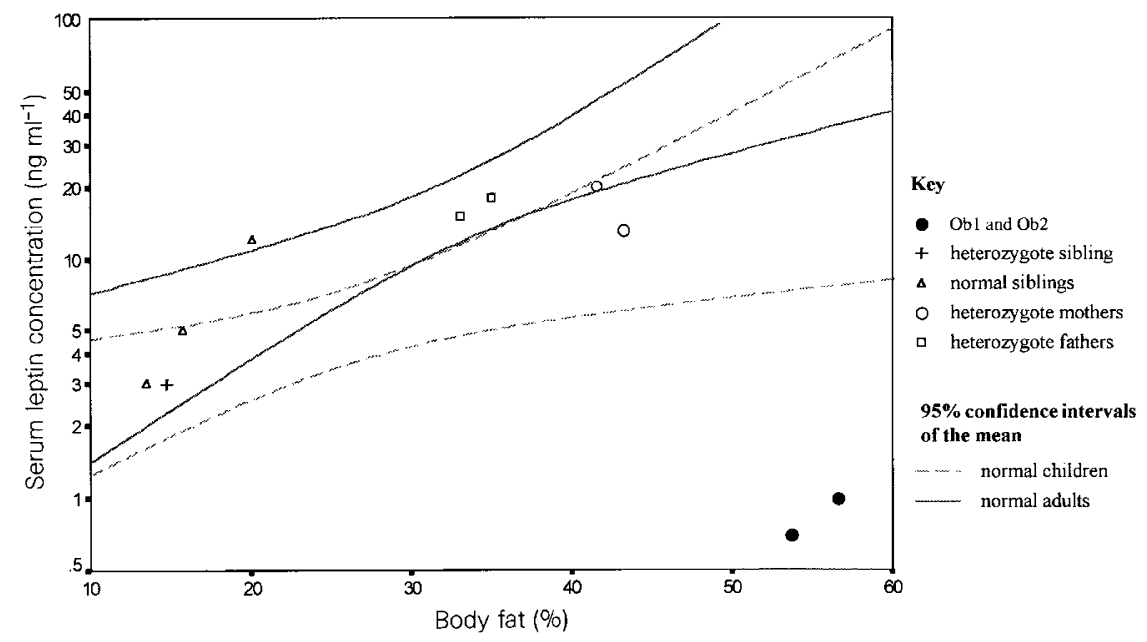

Figure 2 Serum leptin concentrations in $\mathrm{Ob} 1$ and $\mathrm{Ob} 2$ deviate markedly from the normal relationship between percentage body fat and serum leptin. Serum leptin concentrations were measured by radio-immunoassay in the probands, their relatives, adult and prepubertal control subjects. As expected, serum leptin levels in both adult and prepubertal controls correlated positively with estimates of percentage body fat. The serum leptin levels of Ob1 and Ob2 were markedly reduced, being the lowest recorded in this study at 1.0 and $0.7 \mathrm{ng} \mathrm{m}^{-1}$, respectively. Moreover, the finding of low circulating leptin in Ob1 and Ob2 represents a marked deviation from the expected relationship between percentage body fat and serum leptin. This relationship was not markedly different in the relatives who were heterozygous for the frame-shift mutation compared either to family members who were homozygous for the wild-type sequence or to unrelated control subjects. 
in Ob1 and Ob2. Even if this were the case, it is unlikely that the mutant leptin would have any biological activity, as it lacks the carboxy-terminal cysteine that is required for intra-chain disulphide bonding. Mutation of this cysteine has been reported to render the protein biologically inactive ${ }^{13}$. The coexistence in Ob1 and $\mathrm{Ob} 2$ of low levels of immunoreactive serum leptin, gross obesity and a homozygous frame-shift mutation of the leptin gene are, therefore, likely to be causally linked.

The frame-shift mutation may adversely affect serum leptin levels in several ways. First, premature stop codons frequently result in instability of mRNA and a low level of steady-state mRNA ${ }^{14}$. Second, the introduction of an aberrant stretch of amino-acid sequence into the native peptide may disrupt the intracellular targeting and secretion of leptin, as is suggested by the transfection experiments in $\mathrm{CHO}$ cells.

The $o b / o b$ mouse is of normal weight at birth, but rapidly exhibits hyperphagia and is characterized by several phenotypic abnormalities and severe obesity. We studied the phenotype of subjects Ob1 and $\mathrm{Ob} 2$ to determine the degree of similarity between the murine and human syndromes of congenital leptin deficiency. Given the ethical constraints on the study of prepubertal children and our concern to conform to parental wishes, phenotypic characterization was restricted to clinical observations, including auxology, and the measurement of simple biochemical parameters (Table 1). Ob1, a female, had a normal birthweight of $3.46 \mathrm{~kg}$, but gained weight rapidly in the early postnatal period. Her weight deviated from predicted centiles by 4 months of age (Fig. 3a). At the age of 8 years, Ob1 weighs $86 \mathrm{~kg}$ ( $>99.6$ th centile), her percentage body fat is $57 \%$ (reference range for children, 15-25\%), and her height is $137 \mathrm{~cm}$ (75th centile). As a result of her obesity she developed abnormalities of growth in the long bones of her legs, resulting in the need for corrective limb surgery. She underwent liposuction of lower-limb fat in 1994 in an attempt to improve her mobility.

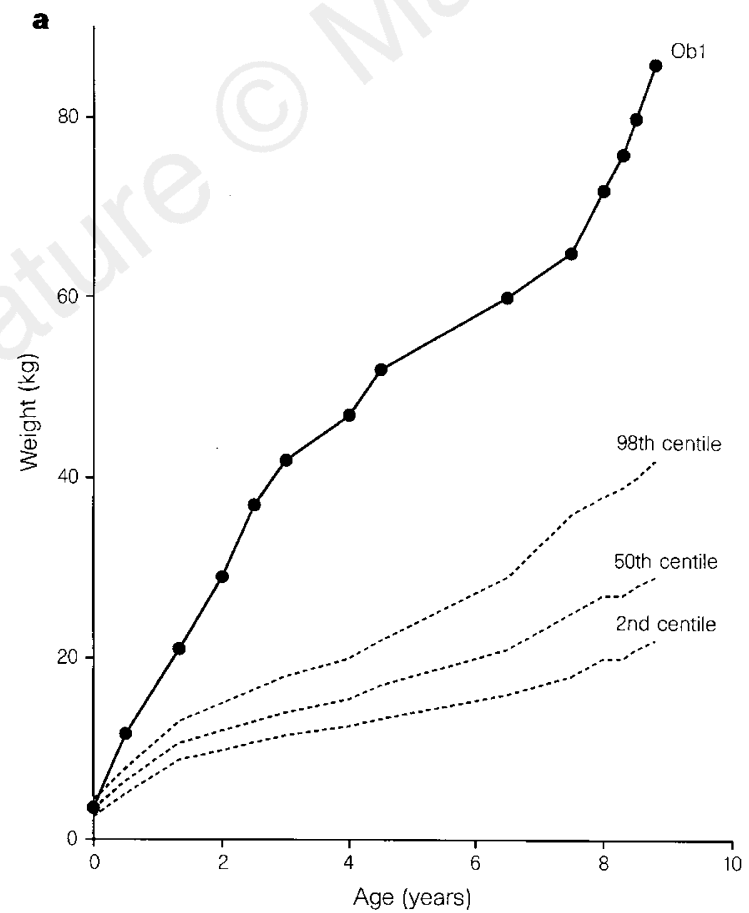

Figure $3 \mathrm{Ob} 1$ and $\mathrm{Ob} 2$ had normal birthweights but rapidly developed severe postnatal obesity. a, Auxology of proband Ob1. Ob1's birthweight was at the 50th centile. By 4 months of age her weight was above the 98th centile. She is now aged 8 years. Her current height, $137 \mathrm{~cm}$, is on the 75th centile for girls. Her current weight is $86 \mathrm{~kg}$, and her mobility is severely impaired by her extreme obesity. $\mathbf{b}$,
$\mathrm{Ob} 2$ is a cousin of Ob1 and is now aged 2 years. He had a normal weight at birth $(3.53 \mathrm{~kg})$ but rapidly became obese, deviating from predicted centiles for weight by 3 months of age (Fig. 3b). He currently weights $29 \mathrm{~kg}$ (>99.6th centile), with $54 \%$ body fat. $\mathrm{He}$ has difficulty in walking because of extreme obesity. His current height is $89 \mathrm{~cm}$ (75th centile). In contrast to $o b / o b$ mice, which show stunted linear growth, the heights of both $\mathrm{Ob} 1$ and $\mathrm{Ob} 2$ are at the 75 th centile. However, given the age of the subjects it is not possible to comment on the future effects of leptin deficiency on the pubertal growth spurt and final adult height of these children.

Although a formal assessment of appetite has not been conducted, there is a clear history of marked hyperphagia, with both children noted from early infancy to be constantly hungry, demanding food continuously and eating considerably more than their siblings. Thus, in both mice and humans, congenital leptin deficiency is associated with a normal birthweight followed by the rapid development of severe obesity associated with hyperphagia and impaired satiety. Detailed assessment of energy expenditure has not yet been possible in these children, although their mean body temperatures are within the normal range $\left(36-37^{\circ} \mathrm{C}\right)$.

The $o b / o b$ mice are also characterized by hypogonadotropic hypogonadism, resulting in sterility. As both $\mathrm{Ob} 1$ and $\mathrm{Ob} 2$ are both clinically prepubertal, with serum concentrations of luteinizing hormone, follicle-stimulating hormone, oestradiol and testosterone at prepubertal levels (Table 1), the effects of congenital leptin deficiency on the human reproductive system cannot yet be established in these children. In contrast to $o b / o b$ mice, which are markedly hypercortisolaemic, plasma cortisol levels at 9:00 in both children are within the reference range, with Ob1 having a slight increase in 9:00 plasma adrenocorticotropic hormone (Table 1). However, the administration of $1 \mathrm{mg}$ of dexamethasone at 24:00 to Ob1 completely suppressed urinary free cortisol to $<17 \mathrm{nmoll}^{-1}$.

Fasting plasma glucose was normal in both children, but fasting

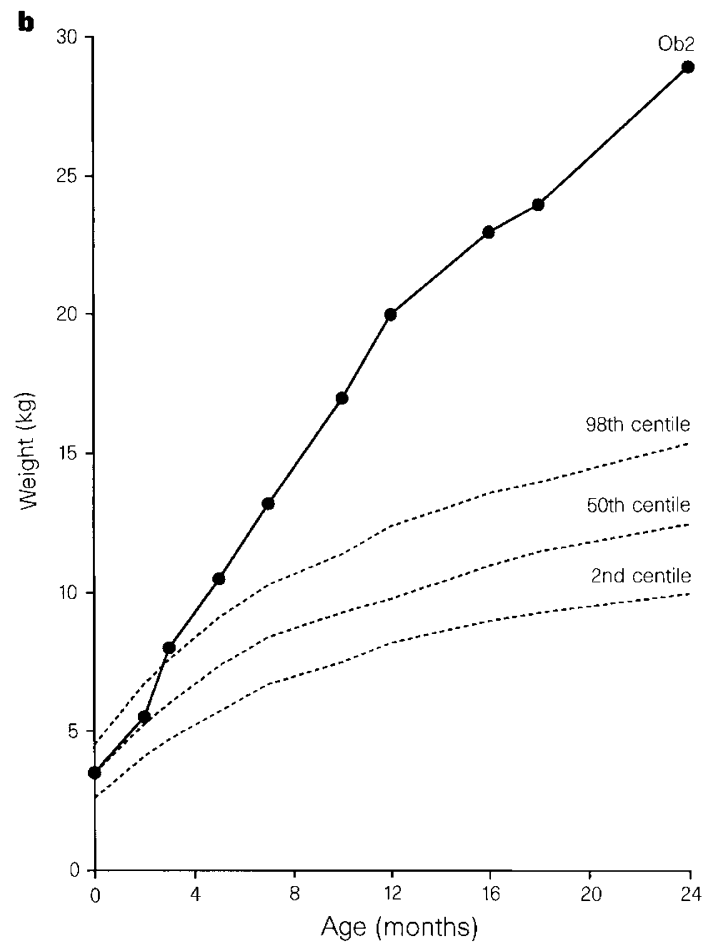

Auxology of proband Ob2. Ob2 is a first cousin of Ob1 and both sets of parents are related. Ob2's birthweight was on the 50th centile for boys. By 3 months his weight was above the 98th centile. He is now aged 2 years. His current height, $89 \mathrm{~cm}$, is at the 75th centile. His current weight is $29 \mathrm{~kg}$, and his mobility is also severely impaired by extreme obesity. 
insulin levels were elevated in Ob1, consistent with the hyperinsulinaemia and insulin resistance seen in $o b / o b$ mice (Table 1). Furthermore, the markedly higher plasma insulin concentration in $\mathrm{Ob} 1$ compared to $\mathrm{Ob} 2$ suggests that insulin resistance may worsen with age in human leptin-deficient states.

Although thyroid dysfunction is not a consistent feature of the phenotype of $o b / o b$ mice $^{15}$, a slight elevation of thyroid-stimulating hormone was noted in both children. The detection of a mild dysfunction of the pituitary-thyroid axis in these leptin-deficient children may represent a species difference, or may simply reflect the fact that normal ranges for serum thyroid-stimulating hormone have been defined more precisely for humans.

Thus, congenital deficiency of leptin in humans results in a phenotype with striking similarities to that seen in mice (severe obesity, hyperphagia and hyperinsulinaemia). The human probands seem to differ from $o b / o b$ mice in that they do not show impaired linear growth, nor do they have marked hypercortisolaemia or hyperglycaemia. Whether the latter abnormalities will appear with time in the human probands, or are absent as a result of intrinsic species differences or the retention of a residual amount of leptin bioactivity in $\mathrm{Ob} 1$ and $\mathrm{Ob} 2$, remains to be established.

The fact that all four parents and one of the four siblings of the probands were heterozygous for the frame-shift mutation in the leptin gene allowed us to examine whether this genotype was associated with any phenotypic abnormalities in humans. None of the four heterozygous parents, nor the one heterozygous sibling, were morbidly obese (Fig. 2), a finding consistent with the absence of severe obesity in the murine $o b$ heterozygotes ${ }^{16}$. Additionally, in the heterozygote relatives, the relationship between percentage body fat and serum leptin concentration was not significantly different from that seen in control subjects (Fig. 2). It should be pointed out that the control subjects in these studies were Caucasians from the UK, whereas the probands and their family members are all of Pakistani descent. However, to our knowledge, no consistent differences in serum leptin levels, other than those attributable to ethnic variations in body fat content, have been reported in subjects of different ethnic origins ${ }^{17}$. Thus, it is unlikely that the validity of the results is seriously affected by lack of matching for ethnicity. The absence of morbid obesity or a marked reduction in measurable serum leptin levels in the heterozygous relatives of the probands suggests either that fine tuning of leptin expression is not required for weight control in humans, or that compensatory mechanisms influencing expression of the wild-type allele are stimulated in the presence of an inactivating mutation in the other allele. However, definitive statements regarding potentially subtle effects of heterozygosity will require detailed studies of body composition and energy expenditure in these subjects and in ethnically matched controls.

In conclusion, the findings in subjects $\mathrm{Ob} 1$ and $\mathrm{Ob} 2$ strongly suggest that leptin critically influences energy balance in prepubertal humans. Our findings do not exclude an additional role for leptin in the initiation of puberty ${ }^{18}$ and/or the maintenance of gonadotropin function in postpubertal life ${ }^{19}$. Now that recombinant human leptin is available for investigation in humans, it should be possible to determine whether the correction of leptin deficiency in the two obese propositi might have therapeutic benefits.

\section{Methods}

Control subjects and clinical measurements. Adult control subjects were healthy Caucasians from the UK aged 30-39 years $(n=30)$. Prepubertal control subjects were Caucasian children from the UK aged 1-11 years that were undergoing elective surgery $(n=16)$. No control subject had undergone any recent marked change in body weight. Height $(\mathrm{cm})$ and weight $(\mathrm{kg})$ were measured, and percentage body fat for adults was calculated using Garrow's formula ${ }^{20}$, and estimated for children using Fomon's reference data ${ }^{21}$ with calculations for obese children based on the assumption that excess weight was $80 \%$ fat. The average percentage body fat for a $70-\mathrm{kg}$ UK Caucasian male is
$17 \%$, and for a $60-\mathrm{kg}$ UK Caucasian female is $22-25 \%$. Average percentage body fat in prepubertal children ranges from $15 \%$ to $25 \%$ (ref. 21).

Serum leptin measurements. Serum samples were collected after an overnight fast and immediately frozen at $-20^{\circ} \mathrm{C}$. Samples were thawed once immediately before the assays. Radio-immunoassays were performed using a commercially available kit (Linco Research) with a detection limit of $0.5 \mathrm{ng} \mathrm{m}^{-1}$ and in-house intra- and inter-assay coefficients of variation of 3\% and 5\%, respectively. Serum leptin levels of Ob1 and Ob2 were also measured using a highly sensitive enzyme-linked immunoassay (minimum detection limit, $70 \mathrm{pg} \mathrm{ml}^{-1}$; intra- and inter-assay coefficients of variation were $6.5 \%$ and $8.3 \%$, respectively) (M. Nicolson, Amgen).

Cloning and sequencing of leptin cDNA. Total RNA was reverse-transcribed to first-strand cDNA using AMV reverse transcriptase (Promega). Leptin cDNA (nucleotides 11-527) was amplified by PCR and cloned into the pCR-Script $\mathrm{SK}(+)$ vector using the pCR Script cloning system (Stratagene). Four clones were sequenced using an $\mathrm{ABI} 373$ automated sequencer.

Direct sequencing of leptin genomic DNA. Nucleotides 2536-2760 of leptin genomic DNA were amplified from genomic DNA of the probands and immediate family members by PCR. Sequencing of the PCR product was performed using an ABI 373 automated sequencer.

Single-strand conformation polymorphism analysis. Nucleotides 25362760 of the leptin gene were amplified from genomic DNA of probands and available family members by PCR including $\left[\alpha{ }^{32} \mathrm{P}\right]-\mathrm{dATP}$. The PCR product was diluted with formamide and electrophoresis performed on a $6 \%$ acrylamide gel at room temperature for $6-8 \mathrm{~h}$ at $20 \mathrm{~W}$. The gel was dried and exposed to film for $24 \mathrm{~h}$.

PCR primers and conditions. Amplification of full-length leptin cDNA of Ob2: sense primer, GAACCCTGTGCGGATTCTTG; antisense primer, CAGGAAGAGTGACCTTCAAG; PCR, $1.5 \mathrm{mM} \mathrm{MgCl} 2,\left(94^{\circ} \mathrm{C} 1 \mathrm{~min}, 55^{\circ} \mathrm{C} 1 \mathrm{~min}\right.$, $\left.72^{\circ} \mathrm{C} 1 \mathrm{~min}\right)$ for $1 \mathrm{cycle},\left(94^{\circ} \mathrm{C} 1 \mathrm{~min}, 55^{\circ} \mathrm{C} 1 \mathrm{~min}, 72^{\circ} \mathrm{C} 1 \mathrm{~min}\right)$ for 40 cycles. Amplification of leptin from genomic DNA: sense primer, CCAACGACCTGGAGAACCTCCGGGATC; antisense primer, CAGGAAGAGTGACCTTCAAG; PCR, $1.5 \mathrm{mM} \mathrm{MgCl}_{2},\left(94^{\circ} \mathrm{C} 1 \mathrm{~min}, 55^{\circ} \mathrm{C} 1 \mathrm{~min}, 72^{\circ} \mathrm{C} 1 \mathrm{~min}\right)$ for $1 \mathrm{cycle},\left(94^{\circ} \mathrm{C}\right.$ $1 \mathrm{~min}, 55^{\circ} \mathrm{C} 1 \mathrm{~min}, 72^{\circ} \mathrm{C} 1 \mathrm{~min}$ ) for 30 cycles. Primer used in sequencing of PCR products: antisense, GTCCTGCAGAGACCCCTGCAGCCTGCT.

Transfection studies. Wild-type and mutant leptin cDNAs (Amgen) were inserted into the expression vector pRc. CMV (Invitrogen) using XbaI and ApaI. Sub-confluent CHO.K1 cells grown in four-well plates were transfected with the plasmids indicated using Lipofectamine according to the manufacturer's instructions (Gibco BRL). Approximately $24 \mathrm{~h}$ after transfection, immunopreciptiation of cell lysates and cultured media was performed using polyclonal anti-leptin antibody, PC3 (Amgen). Immunoprecipitates were electrophoresed on 15\% SDS-PAGE, transferred to PVDF membrane (Immobilon), and probed with PC3 antibody and ${ }^{125}$ I-labelled goat antirabbit secondary antibody (Cal Biochem). Results were analysed using a Fujix BAS 2000 phosphorimager.

Received 4 March; accepted 30 May 1997

1. Zhang, Y. et al. Positional cloning of the mouse obese gene and its human homologue. Nature 372, 425-432 (1994).

Maffei, M. et al. Increased expression in adipocytes of $o b$ RNA in mice with lesions of the hypothalamus and with mutations at the $d b$ locus. Proc. Natl Acad. Sci. USA 92, 6957-6960 (1995).

3. Stephens, T. W. et al. The role of neuropeptide $\mathrm{Y}$ in the antiobesity action of the obese gene product. Nature 377, 530-534 (1995).

4. Vaisse, C. et al. Leptin activation of Stat 3 in the hypothalamus of wild type and $o b / o b$ mice but not $d b /$ $d b$ mice. Nature Genet. 14, 95-97 (1996).

5. Pelleymounter, M. A. et al. Effects of the obese gene product on body weight regulation in $o b / o b$ mice. Science 269, 540-543 (1995).

6. Halaas, J. L. et al. Weight-reducing effects of the plasma protein encoded by the obese gene. Science 269, 543-546 (1995).

7. Campfield, L. A., Smith, F. J., Guisez, Y., Devos, R. \& Burn, P. Recombinant mouse ob protein: Evidence for a peripheral signal linking adiposity and central networks. Science 269, 546-549 (1995).

8. Chen, G. et al. Disappearance of body fat in normal rats induced by adenovirus-mediated leptin gene therapy. Proc. Natl Acad. Sci. USA 93, 14795-14799 (1996).

9. Maffei, M. et al. Absence of mutations in the human $o b$ gene in obese/diabetic subjects. Diabetes 45, 679-682 (1996)

10. Considine, R. V. et al. Evidence against either a premature stop codon or the absence of obese gene mRNA in human obesity. J. Clin. Invest. 95, 2986-2988 (1995).

11. Bouchard, C. The causes of obesity: advances in molecular biology but stagnation on the genetic front. Diabetologia 39, 1532-1533 (1996).

12. Maffei, M. et al. Leptin levels in human and rodent, measurement of plasma leptin and $o b$ RNA in obese and weight-reduced subjects. Nature Med. 1, 1155-1161 (1995).

13. Zhang, F. et al. Crystal structure of the obese protein leptin-E100. Nature 387, 206-209 (1997).

14. Krawczak, M., Reiss, J. \& Cooper, N. The mutational spectrum of single base-pair substitutions in mRNA splice junctions of human genes: causes and consequences. Hum. Genet. 90, 41-54 (1992). 
15. York, D. A., Otto, W. \& Taylor, T. G. Thyroid status of obese (ob/ob) mice and its relationship to adipose tissue metabolism. Comp. Biochem. Physiol. 590, 59-65 (1978).

16. Coleman, D. L. Obesity genes: beneficial effects in heterozygous mice. Science 203, 663-665 (1979). 17. Ravussin, E. et al. Relatively low plasma leptin concentrations preceed weight gain in Pima Indians. Nature Med. 3, 238-240 (1997).

18. Chehab, F. F., Mounzih, K., Lu, R. \& Lim, M. E. Early onset of reproductive function in normal female mice treated with leptin. Science 275, 88-90 (1997).

19. Ahima, R. S. et al. Role of leptin in the neuroendocrine response to fasting. Nature 382, 250-252 (1996)

20. Garrow, J. S. \& Webster, J. Quetelet's Index $\left(\mathrm{W} / \mathrm{H}^{2}\right)$ as a measure of fatness. Int. J. Obes. 9, 147-153 (1985).

21. Fomon, S. J., Haschke, F., Ziegler, E. E. \& Nelson, S. E. Body composition of reference children from birth to age 10 years. Am. J. Clin. Nutr. 35, 1169-1175 (1982).

Acknowledgements. We thank S. Jebb for help with analysis of body composition; C. N. Hales, S. Kumar A. Kelly and P. Raggett for access to control samples; A. Roberts for help with clinical studies; M. McCaleb, F. Martin, N. Hernday, C. N. Hales, A. Krook, S. Jebb, A. Prentice and N. Finer for discussions; T. M. Cox V. K. K. Chatterjee and P. Luzio for reading the manuscript; and M. Flint for secretarial assistance. This research was supported by grants from the Wellcome Trust, the British Diabetic Association and a Medical Research Council (UK) studentship to C.T.M. H.R. is supported by the TMR programme of the EC.

Correspondence and requests for materials should be addressed to S.O.R. (e-mail: sorahill@hgmp.mrc. ac.uk).

\section{Fringe modulates}

\section{Notch-ligand interactions}

\section{Vladislav M. Panin ${ }^{\star}$, Venizelos Papayannopoulos*,} Richa Wilson ${ }^{*}$ Kenneth D. Irvine

Waksman Institute and Department of Molecular Biology and Biochemistry, Rutgers, The State University, Piscataway, New Jersey 08855, USA

* These authors contributed equally to this work

The Notch family of transmembrane receptor proteins mediate developmental cell-fate decisions ${ }^{1}$, and mutations in mammalian Notch genes have been implicated in leukaemia, breast cancer, stroke and dementia ${ }^{2-4}$. During wing development in Drosophila, the Notch receptor is activated along the border between dorsal and ventral cells $s^{5-7}$, leading to the specification of specialized cells that express Wingless (Wg) and organize wing growth and patterning ${ }^{6,8,9}$. Three genes, fringe (fng), Serrate (Ser) and Delta $(D l)$, are involved in the cellular interactions leading to Notch activation $^{7,9-15}$. Ser and $\mathrm{Dl}$ encode transmembrane ligands for Notch $^{16,17}$, whereas $f n g$ encodes a pioneer protein ${ }^{10}$. We have investigated the relationship between these genes by a combination of expression and coexpression studies in the Drosophila wing. We found that Ser and $\mathrm{Dl}$ maintain each other's expression by a positive feedback loop. $\mathrm{fng}$ is expressed specifically by dorsal cells and functions to position and restrict this feedback loop to the developing dorsal-ventral boundary. This is achieved by fng through a cell-autonomous mechanism that inhibits a cell's ability to respond to Serrate protein and potentiates its ability to respond to Delta protein.

Serrate protein (Ser) seems to act as a signal from dorsal cells that activates Notch in ventral cells, whereas Delta protein (Dl) seems to act as a signal from ventral cells that activates Notch in dorsal cells ${ }^{7,9.11-15}$. Both of these proteins are broadly expressed during early wing development: $\mathrm{Dl}$ is initially expressed by all wing cells and Ser is initially expressed by all dorsal wing cells. However, their expression soon becomes restricted to the dorsal-ventral (D-V) boundary of the wing (Fig. 1b-d) $)^{7,9,11,13,14}$. This observation suggests that, as well as being involved in signalling between dorsal and ventral cells, Ser and $\mathrm{Dl}$ also respond to $\mathrm{D}-\mathrm{V}$ cell interactions, and so they may regulate each other's expression. To examine this, transgenic flies containing UAS-Ser (ref. 12) or UAS-Dl (ref. 14) were crossed to flies containing ptc-Gal4 (ref. 18), which drives expression in a stripe along the anterior side of the anterior-posterior $(\mathrm{A}-\mathrm{P})$ compartment boundary (Fig. 1a) ${ }^{19}$. The ability of Ser to induce Dl expression, and of Dl to induce Ser expression, was then assayed by antibody staining of mid third-instar wing imaginal discs.
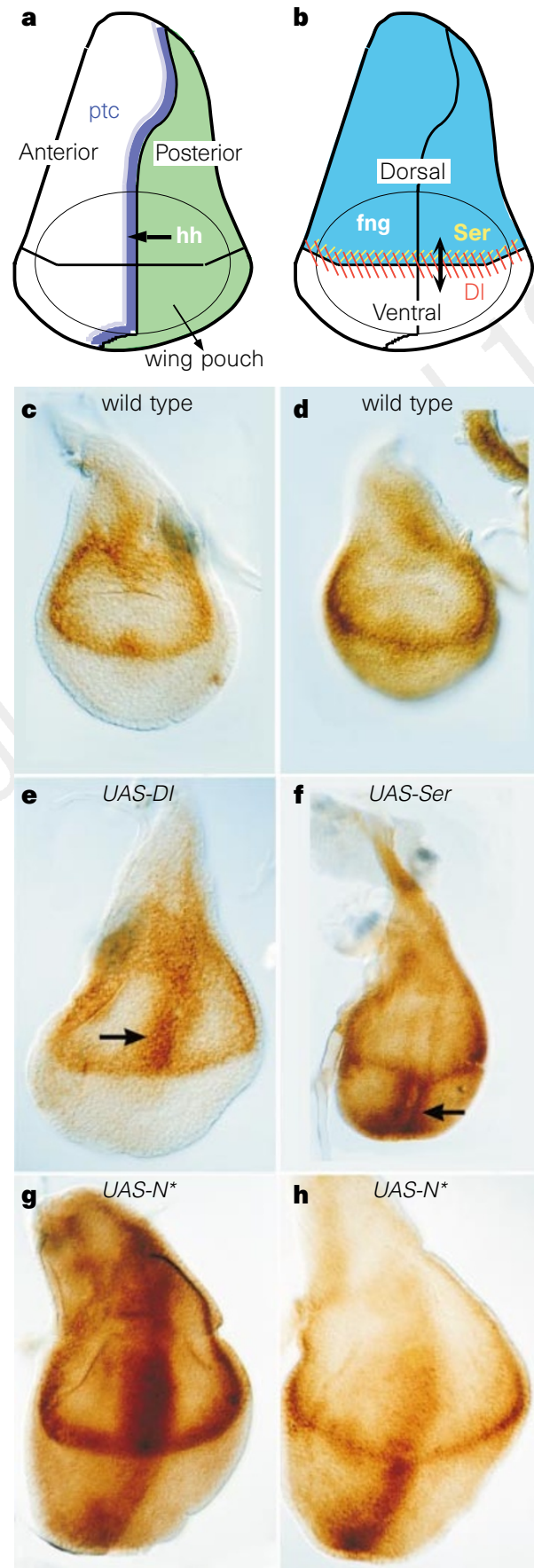

Figure 1 Ser and DI expression and feedback regulation in the wing imaginal disc. Dorsal is up, anterior to the left. a, Schematic representation of A-P compartmental division of the wing disc; expression of the P-compartment signal, Hedgehog (Hh, green), and of Patched (Ptc, purple) is shown. The wing pouch, which is the portion of the disc that gives rise to the adult wing blade, is demarcated by an oval. b. Schematic representation of $D-V$ compartmental division of the wing disc. The expression patterns of Fng (blue), Ser (yellow hatching) and DI (red hatching) are dynamic; expression from early to midthird instar is shown. $\mathbf{c}-\mathbf{h}$, Expression in mid third instar wing imaginal discs (at same magnification) of $\operatorname{Ser}(\mathbf{c}, \mathbf{e}, \mathbf{g})$ and $\mathrm{DI}(\mathbf{d}, \mathbf{f}, \mathbf{h})$. c, d, Wild type. e, UAS-D130A ptcGa/4 raised at $25^{\circ} \mathrm{C}$; arrow points to ectopic expression of Ser in dorsal cells.f, UAS-SerptcGa/4 raised at $25^{\circ} \mathrm{C}$; arrow points to ectopic expression of $\mathrm{DI}$ in ventral cells. Previous studies of Ser signalling have indicated that cells expressing Ser are themselves refractory to Ser; this presumably accounts for the restriction of $\mathrm{DI}$ induction to the edges of the Ptc expression stripe. $\mathbf{g}, \mathbf{h}$, UASactivated-Notch ptc-Gal4 raised at $18^{\circ} \mathrm{C}$. 